\title{
Active control and energy cost assessment of a rotating machine
}

\author{
Jarir Mahfoud*, Yan Skladanek and Johan Der Hagopian \\ Université de Lyon, CNRS, INSA-Lyon, LaMCoS UMR5259, Villeurbanne Cedex, France
}

Received 5 August 2009

Accepted 30 March 2010

\begin{abstract}
The performances for controlling a rotating machine by using either an Electromagnetic Actuator or a Piezoelectric Actuator are compared in this work. The aim is to establish selection criteria based on environmental impact. Life Cycle Analysis shows that the operating stage has a considerable impact. In this study, only the operating stage is considered. The energy consumed by the actuators seems to be the appropriate indicator for the same "mechanical" performances. Numerical studies are carried out in order to quantify the energy consumed in each case. Modal control strategy with a fuzzy controller is used. The controller inputs are displacements and velocities. The system studied is modeled by using finite element method and the electrical circuit of each actuator is modeled by using basic electricity and electromagnetism theories. Several configurations are assessed and defined by using the chosen Functional Unit.

The results obtained show that both controllers are efficient and enable recommendations for optimal control procedures design for the energy consumed.
\end{abstract}

Keywords: Control, rotordynamics, life cycle analysis, energy consumption

\section{Nomenclature}

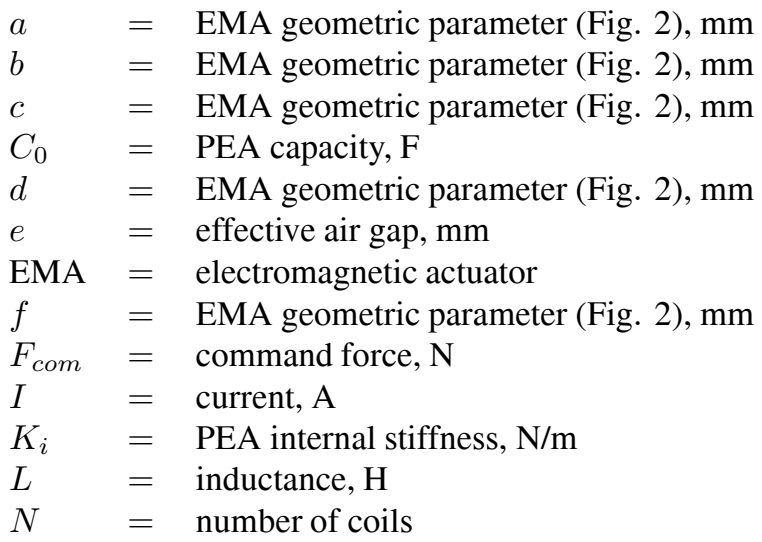

${ }^{*}$ Corresponding author: Dr. Jarir Mahfoud, Université de Lyon, Laboratoire de Mécanique des Contacts et des Structures- LaMCoS, UMR CNRS, 5259, Institut National des Sciences Appliquées de Lyon, Bâtiment Jean d'Alembert, 18-20, rue des Sciences, 69621 Villeurbanne Cedex, France. Tel.: +33 4724389 39; Fax: +33 47243 89 30; E-mail: Jarir.mahfoud@insa-lyon.fr. 


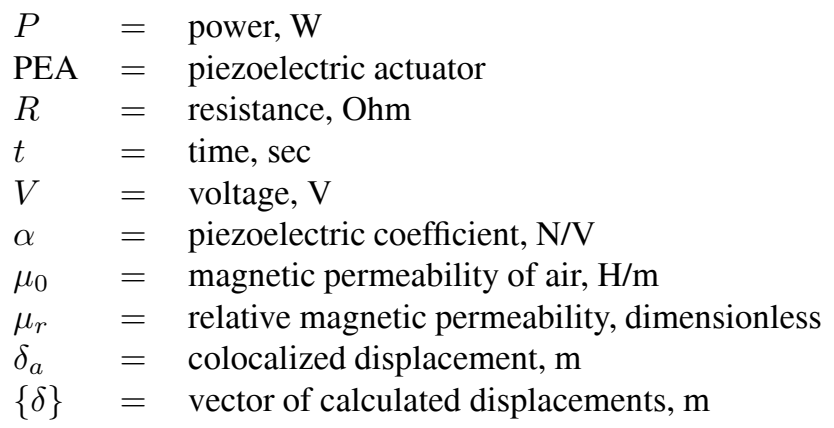

\section{Introduction}

Life Cycle Assessment (LCA) is an important evaluation and decision-aid tool. It is used to analyze environmental problems associated with products and services throughout their full life-cycle. It indicates stages in life-cycle with high environmental impacts and thus provides guidance for optimizing the utilized technology and solutions utilized [1,2]. LCA is an ISO 14040 normalized method for the environmental assessment of industrial systems [3]. In addition, it enables comparing the "environmental impact" between two processes or systems [4-6] as well as the evaluation of their "environmental cost" [7-9]. A substantial part of these environmental costs relate in one way or another to energy consumption. Several contributions in the field of structure vibration control have aimed at quantifying or optimizing energy consumption during the operating stage [10-13].

Control devices (active or passive) are now much used in several fields of engineering where the quest to minimize energy requirements and satisfy the need to establish selection criteria for the "best" control approaches for a rotating machine have become a priority.

This study is a contribution that takes into account eco-indicators when comparing the control performances of a rotating machine by using either ElectroMagnetic Actuators (EMA) or PiezoElectric Actuators (PEA). An initial Life Cycle Analysis approach has shown that the operating stage is that which has the greatest impact, consequently this paper focuses only on this stage.

In the field of turbomachinery, Active Magnetic Bearings (AMB) have been successfully applied in industrial applications [14]. They are well suited for contactless operations such as actuators and sensors in rotating machinery [15-18]. AMB technology in conjunction with conventional bearings is utilized either as an active magnetic damper [19], or for controlling the instability of certain supports such as journal bearings [20,21]. In this case the AMB is considered to be an EMA.

On the other hand, piezoelectric ceramics are widely used for controlling vibration in mechanical systems [22-24]. Several contributions have demonstrated the feasibility of rotor vibration control by using stacked piezoelectric actuators that either act directly on the shaft, or in conjunction with conventional support bearings $[25,26]$.

In a previous study the dynamic behavior of a rotor was controlled by using an active hybrid bearing [27]. The latter was composed of a roller bearing located in an external cage attached to the framework of the test bench by three flexible steel beams. Two PZT stack actuators fixed to the external cage provided command forces for the control. The rotor was efficiently controlled in transient and steady state domains. In this study the objective is to control the dynamic behavior of this rotor by using an active hybrid bearing where the command forces for the control are delivered by EMA.

Numerical simulations are carried out in order to quantify and compare the energy consumed when controlling the rotating machine by using either EMA or PEA. In each case a modal fuzzy controller is used. Obviously, due to the structural arrangement implemented, the two configurations do not have exactly the same dynamic behavior, but the controller gains are calculated in order to obtain dynamic performances of the rotating machine that are as similar as possible. The conditions of comparison are displacement level and settling time due to an impact applied on the rotor at rest, and during the run up (or run down) from 0 to $10000 \mathrm{rev} / \mathrm{min}$.

The paper is divided into several sections: after the brief introduction, the system studied and the corresponding finite element model are presented and then the implemented control approach is described. The Function Unit corresponding to the operating stage is defined. Finally, the results are presented and the main conclusions are summarized in the last section. 


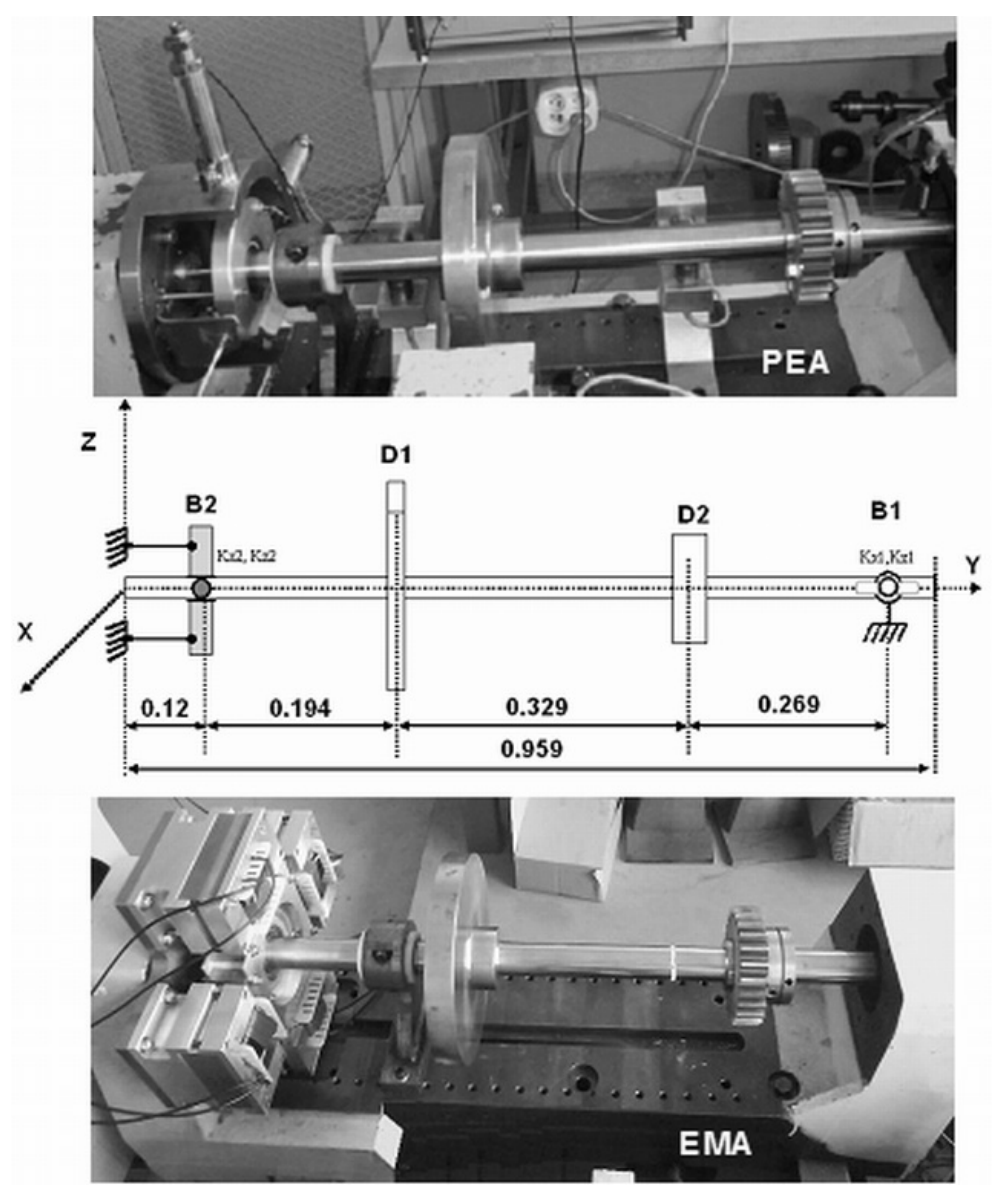

Fig. 1. Photos and diagram of the system studied.

\section{Studied system}

The system studied is a test machine composed of a horizontal flexible shaft of $0.04 \mathrm{~m}$ diameter and two rigid discs (Fig. 1). The shaft is supported by bearings located at its ends: A roller bearing at one end (B2) and two ball bearings at the other end (B1).

The roller bearing is located in a squirrel cage attached to the framework of the test bench by three identical flexible steel beams (55.0 mm length, $5.2 \mathrm{~mm}$ diameter). The actuators linked to the external cage constitute the active bearing and provide the active control. The presence of this squirrel cage makes the system slightly dissymmetric. The test rig operates in a frequency range up to $10000 \mathrm{rev} / \mathrm{min}$, including 2 critical speeds (first mode in the lateral directions).

The PEA is composed of two PZT stack actuators (Physik Instrumente P-245.70; $\pm 120 \mu \mathrm{m} ; 2000 \mathrm{~N}$ compression; $300 \mathrm{~N}$ traction) placed in a plane. They are fixed to the external cage by cylindrical steel stems $(15.0 \mathrm{~mm}$ length, $1.2 \mathrm{~mm}$ diameter) so that one end of each stem is bonded to the cage and the other end is bonded to the free end of the actuator. The operating point of the actuators is chosen so that they provide a control force in the range of $\pm 500 \mathrm{~N}$ and the output offset of the power amplifier is adjusted by using a static voltage of $-500 \mathrm{~V}$. The bending stiffness of this setup was determined experimentally by performing a static deformation test described in a previous study [27]. The characteristics of the bearing utilized are presented in Table 1.

Since an EMA can only produce attractive forces, four identical actuators commanded independently are utilized. Each EMA is composed of a ferromagnetic circuit and an electrical circuit. The ferromagnetic circuit is composed by two parts (Fig. 2): an (E) shape which receives the induction coil and an (I) shape part which is fixed on the 
Table 1

Bearing characteristics

\begin{tabular}{lccc}
\hline & B1 & B2 with PEA & B2 with EMA \\
\hline Kxx $(\mathrm{N} / \mathrm{m})$ & $3.5 \mathrm{E} 6$ & $8.7 \mathrm{E} 6$ & $1.39 \mathrm{E} 6$ \\
$\mathrm{Kzz}(\mathrm{N} / \mathrm{m})$ & $8.0 \mathrm{E} 6$ & $6.9 \mathrm{E} 6$ & $1.39 \mathrm{E} 6$ \\
$\mathrm{Cxx}(\mathrm{Ns} / \mathrm{m})$ & 800 & 800 & 800 \\
$\mathrm{Czz}(\mathrm{Ns} / \mathrm{m})$ & 800 & 800 & 800 \\
Mass $(\mathrm{kg})$ & - & 0.970 & 4.921 \\
\hline
\end{tabular}

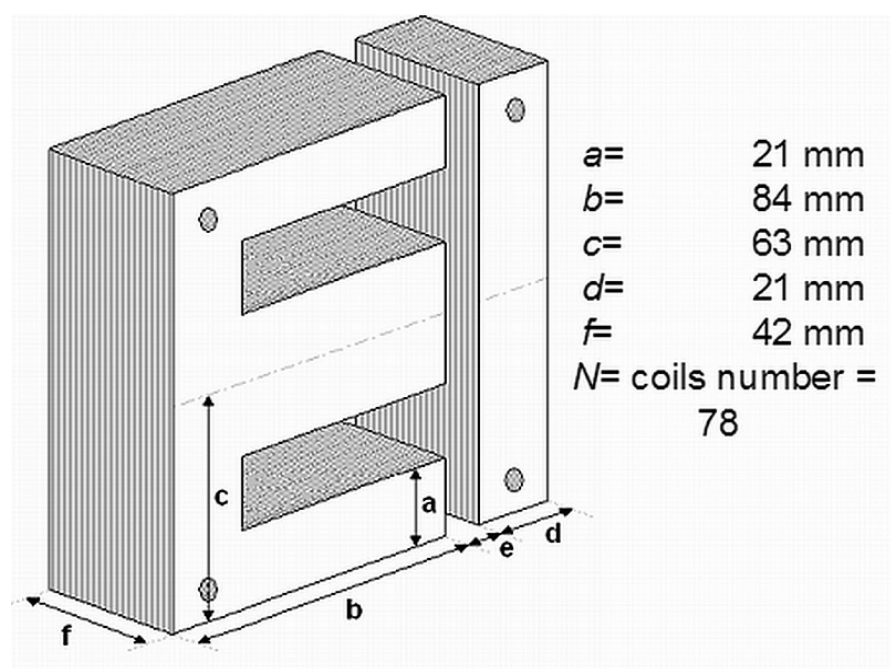

Fig. 2. EMA details.

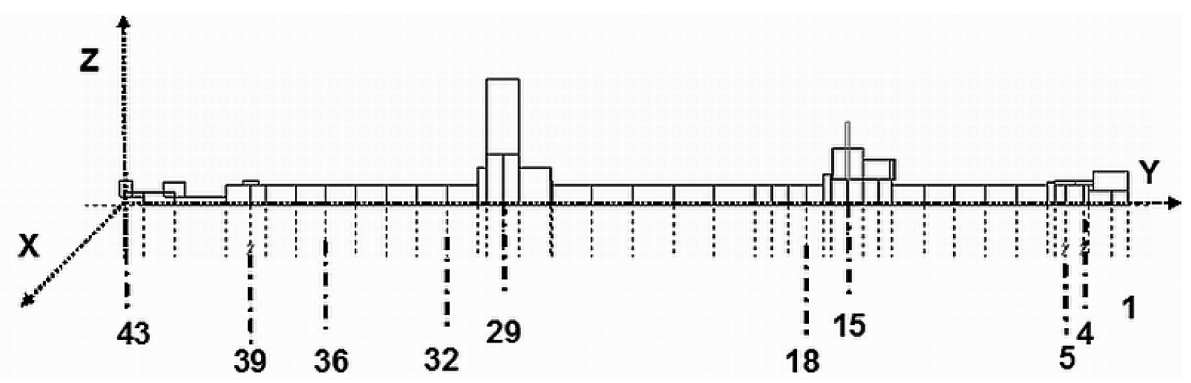

Fig. 3. Finite element model of the system studied.

squirrel cage. Both parts made of assemblies of insulated ferromagnetic sheets. The quality of the ferromagnetic circuit alloy is considered high enough and the nominal air gap between the stator and the beam is small enough to consider magnetic loss as negligible. The actuators are designed to deliver a maximum attraction force of 300 $\mathrm{N}$ for a maximum current of $6.5 \mathrm{~A}$. The mass and stiffness of the active hybrid bearing are estimated by numerical calculations. The resulting radial stiffness is smaller than that obtained for the PEA configuration (Table 1); consequently, the calculated first critical speed is different in both cases.

A finite element model of the test rig is used to carry out the numerical simulations (Fig. 3). The rotor model is composed by the following elements: rigid discs that contribute kinetic energy only; flexible shafts providing both kinetic and strain energy; and bearings with elastic and dissipation characteristics. Regarding the shaft, it is modelled by 22 Timoshenko beam elements, each of which has two nodes and 4 degrees of freedom (two displacements and two rotations) per node. The ROTORINSA ${ }^{\circledR}$ software is used to obtain the modal matrices of the rotor for a null rotational speed. These modal matrices are necessary to calculate the modal state space system representation. The ten first modes are considered. 
Table 2

Calculated frequencies and damping factors

\begin{tabular}{llcc}
\hline & & B2 with PEA & B2 with EMA \\
\hline $\mathrm{X}$ direction & Frequency $(\mathrm{Hz})$ & 66.5 & 49.1 \\
& Damping & 0.02 & 0.02 \\
$\mathrm{Z}$ direction & Frequency $(\mathrm{Hz})$ & 66.8 & 49.8 \\
& Damping & 0.02 & 0.02 \\
\hline
\end{tabular}

Table 3

Fuzzy controller rules

\begin{tabular}{clc}
\hline Rule & Condition & Decision \\
\hline 1 & Positive displacement \& positive velocity & Action \\
2 & Positive displacement \& negative velocity & No action \\
3 & Negative displacement \& positive velocity & No action \\
4 & Negative displacement \& negative velocity & Action \\
\hline
\end{tabular}

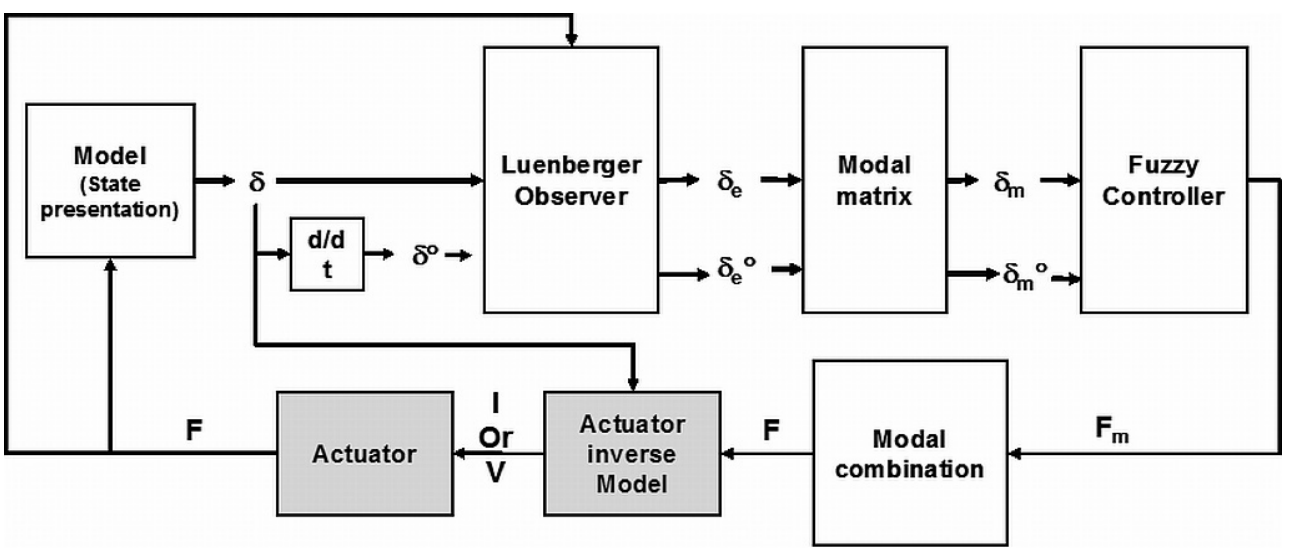

Fig. 4. Schema of the control strategies.

Table 2 presents the calculated frequencies (first critical speed in $\mathrm{X}$ and $\mathrm{Z}$ directions) and damping factors. In the following sections, the system's behavior is simulated by the MATLAB ${ }^{\circledR}$ and SIMULINK ${ }^{\circledR}$ package.

\section{Control approach}

The control strategy is a fuzzy modal controller of Takagi-Sugeno type. It was found to be the best adapted for controlling flexible structure. Moreover, the performances of this type of controller allow taking into account slight nonlinearities and uncertainties due to experimental context [28].

The numerical simulations are performed in a configuration as similar as possible to that of the experiments. Displacements (in both direction X and Z) of node \#33 (position of a measurement plane) and node \# 39 (position of the active bearing) are used. The velocities are obtained by numerical derivations. The controller is then supplied by the modal state vector rebuilt by using a Luenberger observer (Fig. 4). The modal displacements and velocities are the inputs of the fuzzy controller. The principle first consists on the fuzzification of the inputs into qualitative quantities (high, low, etc.) as a function of the maximum and the minimum values of each input through two membership GBELL Matlab ${ }^{\circledR}$ "Positive" and "Negative" functions. The rules that characterize the controller are then defined (see Table 3). Finally the command is obtained after defuzzification. This defuzzification requires knowledge of the fuzzy output variables corresponding to the rules and the aggregation of the latter.

The command force is a weighted sum of the controller's output generated by each modal fuzzy controller and by the integral feedback of the displacements colocalized on the actuator plane. This integral feedback makes it 


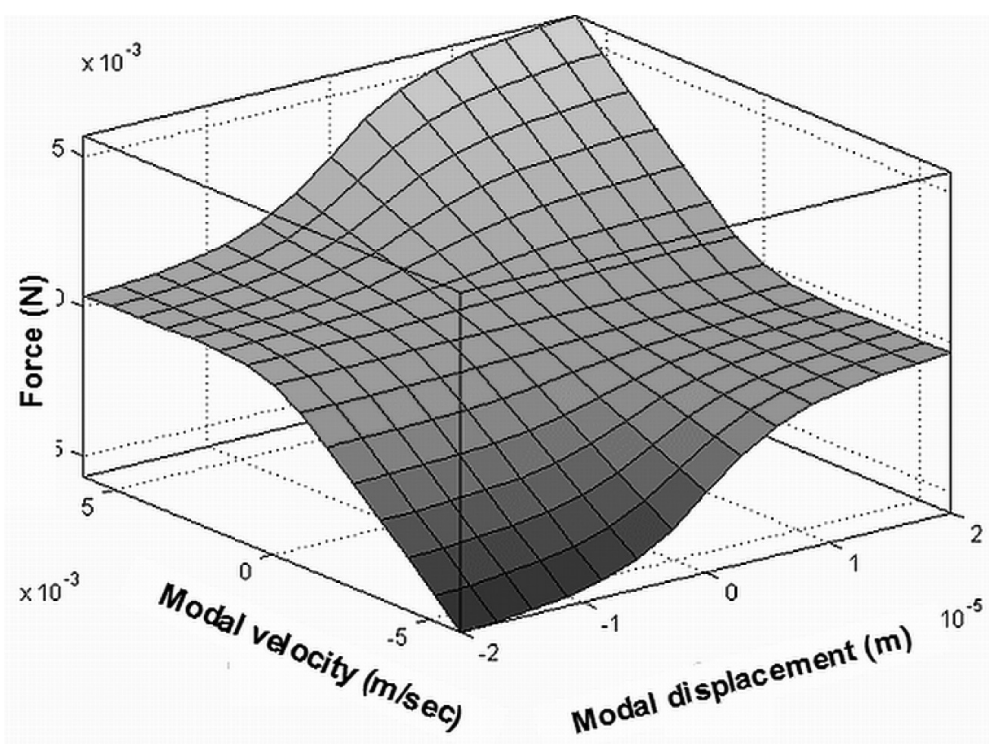

Fig. 5. The output force of the fuzzy controller (Mode \#2).

possible to maintain the static position of the rotor. The output force surface of the fuzzy controller related to the modal inputs of the second mode is presented in Fig. 5.

The control input of an EMA can be either current or voltage. For practical reasons and in order to simplify the electrical model we choose a current control configuration. The control input of a PEA is voltage. The choice of the input for both controllers is done in order to have the most favorable configuration. The behavior of the PEA with current as input is not assessed in this paper.

As the controller's output is the command force, an inverse model of each actuator is used that enables generating the command (either current or voltage) that produces the desired force. The current and voltage are necessary to calculate the energy consumed.

\section{Operating stage analysis}

The LCA considers the full life of a product from the design phase, the acquisition of raw material, product manufacture and the distribution, the use or operating phase and finally the end of life phase. For this study, only the operating stage is considered. Usually, it is necessary to define a Function Unit that enables comparing several approaches for the same operating conditions and service. The FU defined is the levels of displacement due to:

1. an impact applied on the disc D1 at rest,

2. acceleration from 0 to $10000 \mathrm{rev} / \mathrm{min}$ at a rate of $252 \mathrm{rev} / \mathrm{min} / \mathrm{sec}$.

The energy consumed is calculated and compared for the given operating conditions. We assumed that the run up and run down configurations are similar.

Although the control power could be calculated by using the command force and the colocalized velocity, in this study we chose to consider the technology of the actuator used. The power $(P)$ utilized in both configurations can be written as:

$$
P=V I
$$

Where $(I)$ and $(V)$ are the current and the voltage respectively. The energy consumed is then calculated as the integral of the power over the time interval utilized. As the control input of the EMA is the current and the voltage is the input of the PEA, and since the controller output is the command force, it is necessary to formulate an inverse model of each actuator. 


\subsection{PEA model}

Assuming that the PZT undergoes negligible deformation, the relations between mechanical and electrical actuator parameters can be written as [29]:

$$
\begin{gathered}
F=-K_{i} \delta_{a}+\alpha V \\
I=\alpha \dot{\delta}_{a}+C_{0} \dot{V}
\end{gathered}
$$

where $(\alpha)$ is the piezoelectric coefficient, $\left(\delta_{a}, \dot{\delta}_{a}\right)$ the colocalized displacement and velocity respectively, $\left(C_{0}\right)$ and $\left(K_{i}\right)$ the capacity and the internal stiffness of the PEA.

Based on this simplified model, the command voltage can be calculated in relation with the command force $\left(F_{\text {com }}\right)$ and the colocalized displacement $\left(\delta_{a}\right)$ as:

$$
V=\frac{\left(F_{c o m}+\delta_{a} K_{i}\right)}{\alpha}
$$

The PEA characteristics can be either estimated experimentally or calculated by using manufacturer's data. In this study the manufacturer's data are utilized $\left(K_{i}=1.810^{7} \mathrm{~N} / \mathrm{m}, C_{0}=370 \mathrm{nF}, \alpha=1.210^{7} \mathrm{~m} / \mathrm{V}\right)$.

\subsection{EMA model}

Based on magnetic circuit theory and assuming negligible eddy current effects and a conservative flux, the relationship between command force $\left(F_{c o m}\right)$, air gap $(e)$, gap distance $\left(\delta_{a}(t)\right)$ and current $(I)$ could be expressed as [30]:

$$
F_{\text {com }}=\frac{N^{2} \mu_{0} a f I^{2}}{2\left(\left(e+\delta_{a}(t)\right)+\frac{b+c+d-2 a}{\mu_{r}}\right)^{2}}
$$

$a, b, c, d, f$ correspond to the geometrical characteristics of the actuator and $\left(\mu_{0}\right)$ is the magnetic permeability of a vacuum $\left(4 \pi \times 10^{-7} \mathrm{H} / \mathrm{m}\right)$. $\left(\mu_{r}\right)$ is the relative (dimensionless) magnetic permeability which can mainly vary as a function of temperature. Its value is based on the manufacturer's specifications and generally is not known with great accuracy. Its value was determined experimentally by measuring the force generated by an actuator for several air gaps as a function of different increasing and decreasing input currents [31].

Usually a bias current is applied to improve the linearity of the EMA amplifiers. This increases energy consumption significantly. In this study the bias current is not necessary, as the controller output is the command force; also an inverse model of the actuator is used. It enables generating the command current to produce the desired command force and having a linear action block.

The EMA is modeled by a resistance $(R)$ and an inductance $(L)$, while the voltage is calculated as:

$$
V=R I+I \frac{d L}{d t}+L \frac{d I}{d t}
$$

Given the length and diameter of the Copper wire used for the coils, the resistance is calculated (and verified experimentally) to be $0.08 \mathrm{Ohm}$. The inductance is related to the geometrical characteristics of the actuator, the air gap and the gap distance and can be written as:

$$
L(t)=\frac{N^{2} \mu_{0} a f}{\left(e+\delta_{a}(t)\right)+\frac{b+c+d-2 a}{\mu_{r}}}
$$

At rest $\left(\delta_{a}(t)=0\right)$ and for an air gap of $0.5 \mathrm{~mm}$ the inductance is equal to $0.0099 \mathrm{H}$. 

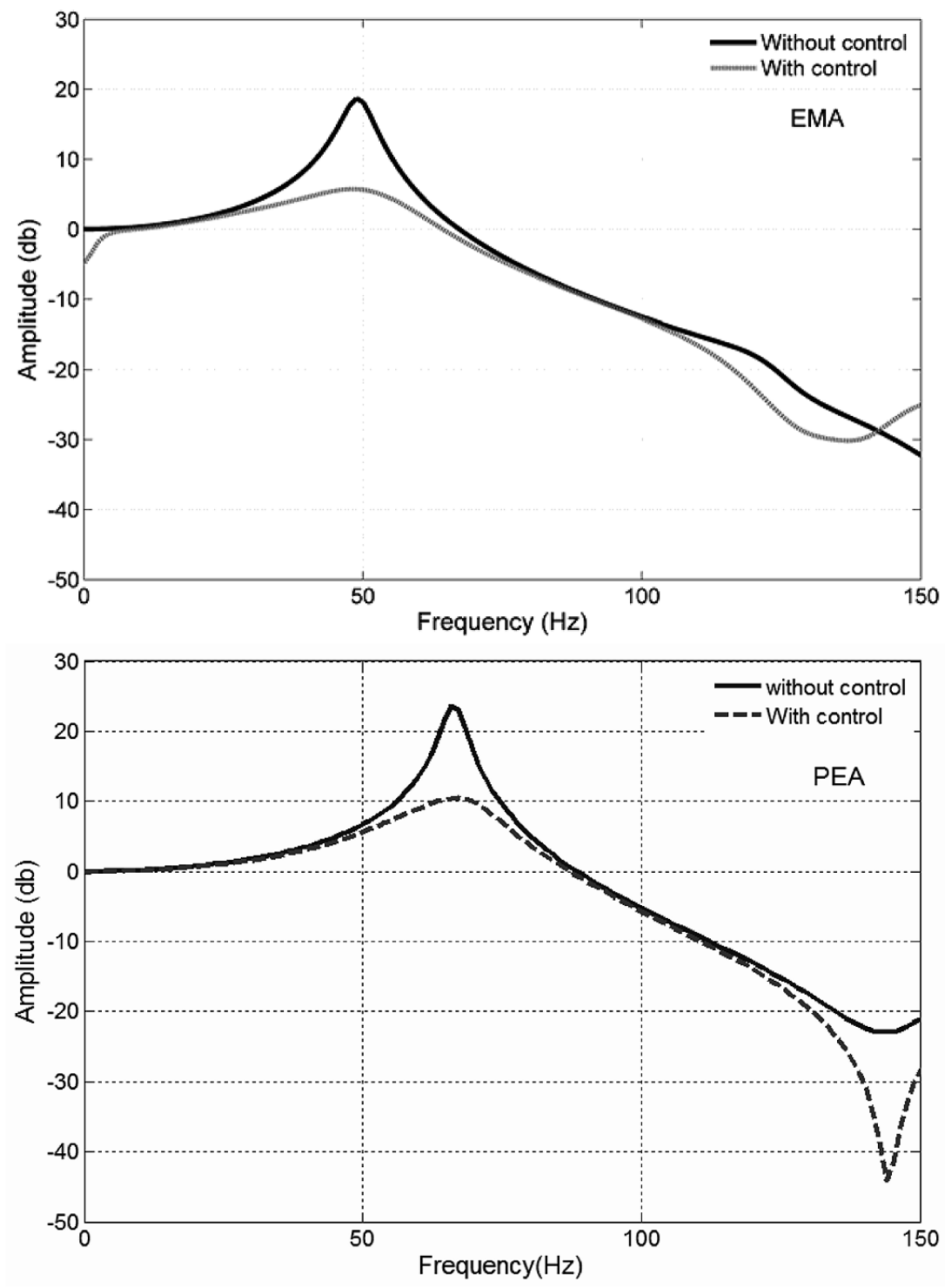

Fig. 6. Bode diagram for EMA and PEA, with and without control, direction X.

\section{Results}

The first step consists in evaluating the efficiency of the controllers. The Bode diagrams, calculated in direction X, of the rotor at rest for both controllers are shown in Fig. 6. Calculations were performed at the position corresponding to node \# 22. It can be observed that the controllers were able to impose a vibration level reduction as high as $15 \mathrm{~dB}$ at the first critical speed. Both controllers seem to be efficient "from a mechanical point of view". The same trends were observed in direction $\mathrm{Z}$.

The second step consists in evaluating the efficiency of the controllers under transient conditions. An impulsive force is applied at disc D1 in direction X, a position corresponding to node\# 29. The displacements with and without control along direction $\mathrm{X}$ are shown in Fig. 7. It can be seen that the setting time was reduced from 0.4 sec to 0.18 sec when using PEA and to $0.15 \mathrm{sec}$ when using EAM. The displacement level is lower in the case of PEA. This is due to the fact that the active hybrid bearing is more rigid because of the pushrods that link the actuators (and its own stiffness) to the squirrel cage. The same trends are observed for direction $\mathrm{Z}$. 

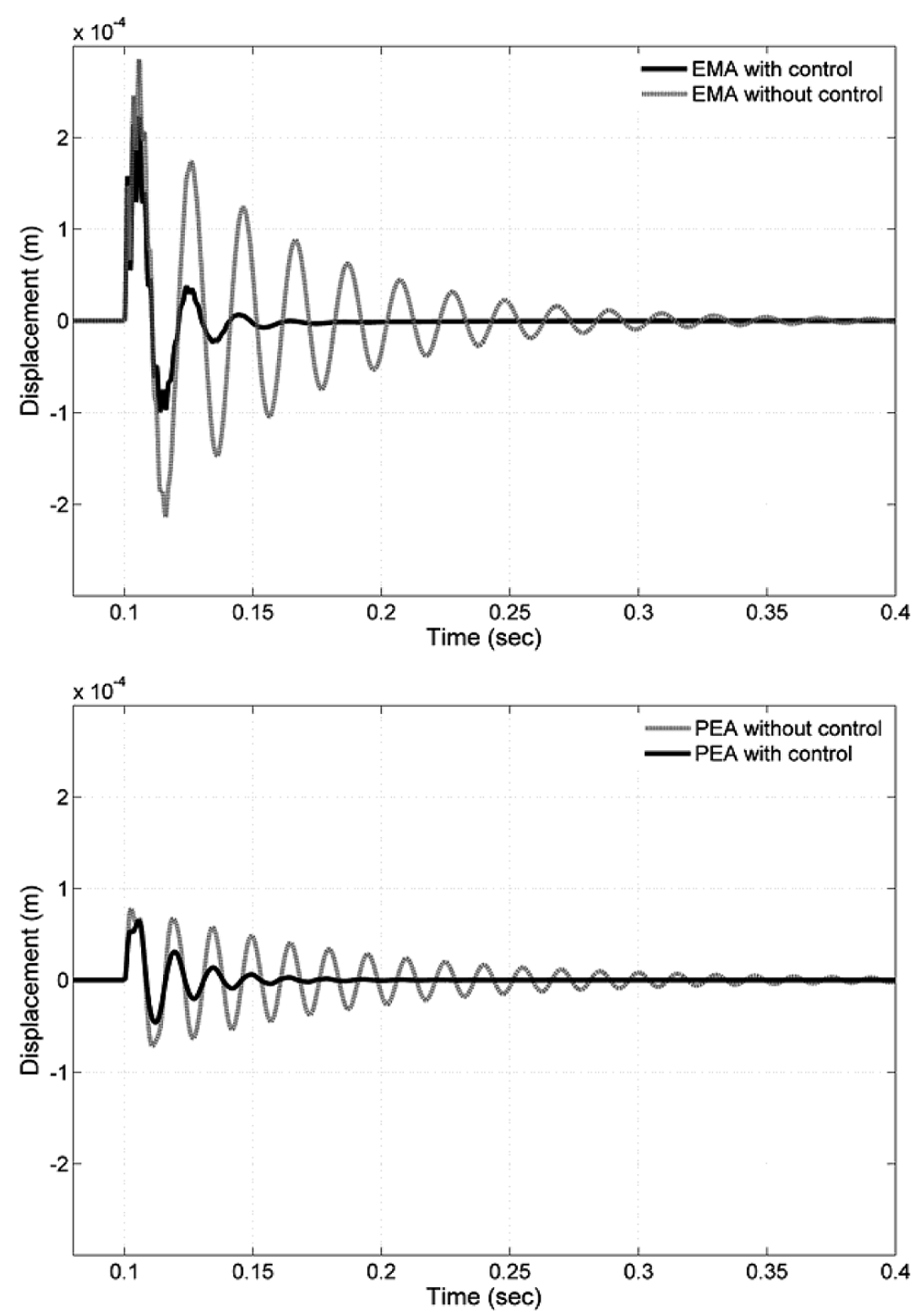

Fig. 7. Response, impact excitation, direction X.

The command forces used for the control are shown in Fig. 8. It can be seen that the EMA force level is lower and has a shorter duration of action. This is due to the fact that the EMA mainly introduces damping.

In order to quantify the energetic cost, the power used by the two actuators is calculated as described previously (Fig. 9).

The total energy consumption is calculated over 1 second (Fig. 10). It is obvious that the PEA has the higher energy consumption, even if the total consumed energy is relatively limited (less than $0.16 \mathrm{~J}$ ).

The third step consists in analyzing the dynamic behavior of the rotor-bearing system in the range from 0 to 10000 $\mathrm{rev} / \mathrm{min}$ with an acceleration rate of $252 \mathrm{rev} / \mathrm{min} / \mathrm{sec}$. A smooth passage through the first critical speed is observed, for both directions $\mathrm{X}$ and $\mathrm{Z}$ at different nodes. The command forces in this case are presented in Fig. 11. The EMA force level is lower, but this level is maintained even after crossing the critical speed. The force level increases for higher speeds that are closer to the next critical speed. 


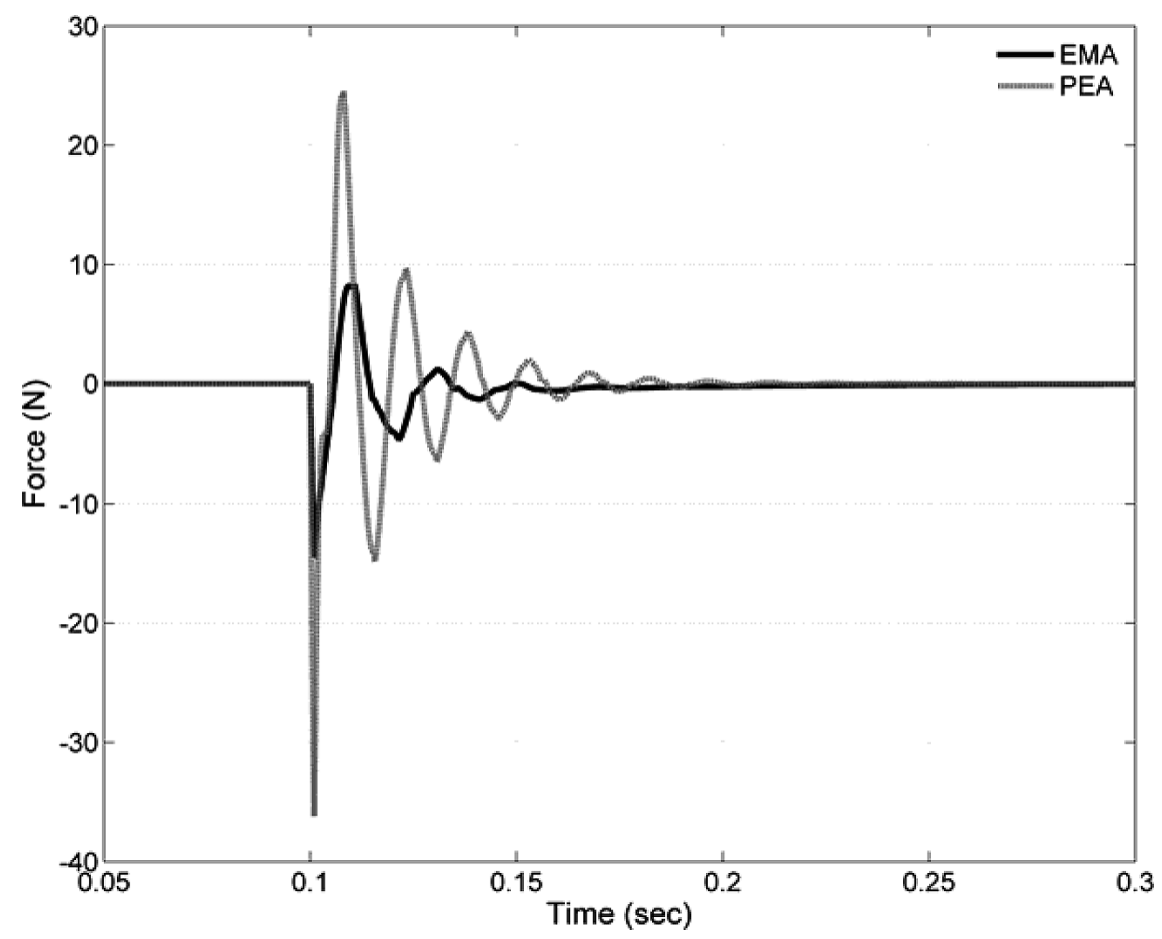

Fig. 8. Command forces, impact excitation.

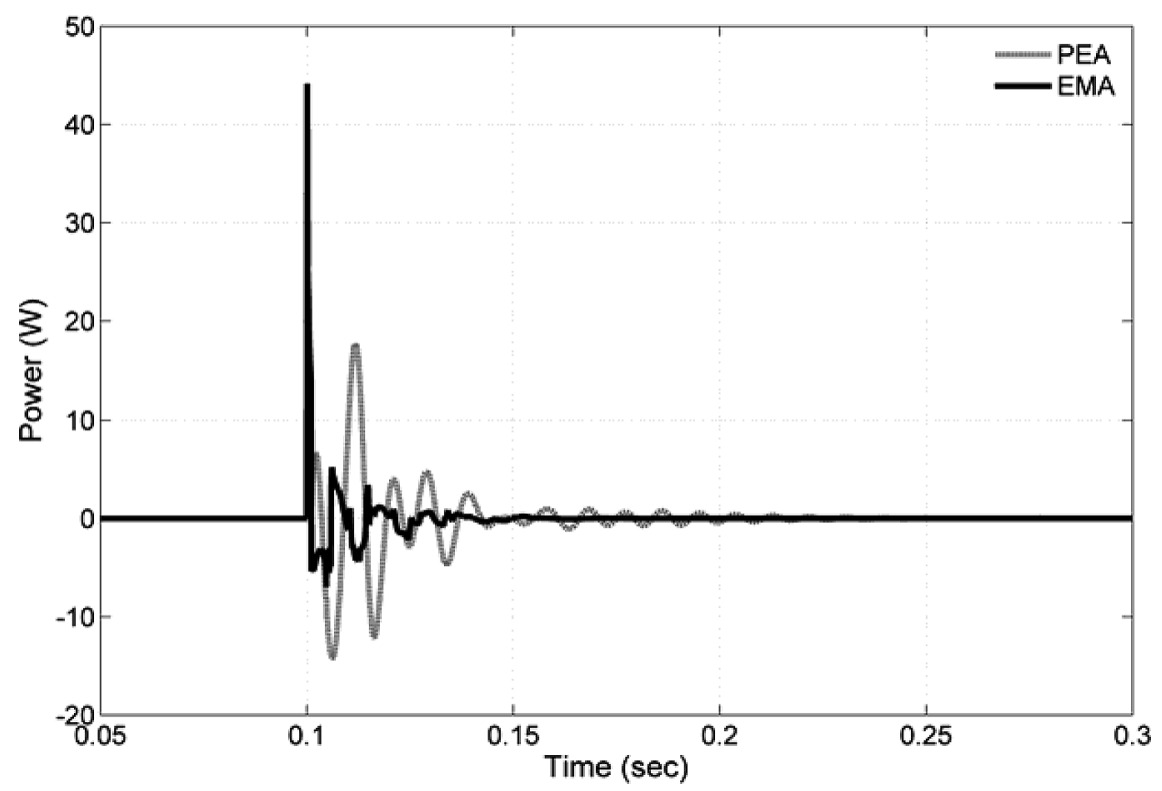

Fig. 9. Power used, impact excitation.

As previously, total energy consumption is calculated for the acceleration duration (Fig. 12). In this case also, the PEA has the higher consumption.

Both actuators continue controlling and consuming energy even for rotation speeds higher than the first critical speed where the displacement levels decrease significantly. This is caused by the inputs (displacements and velocities) of the controller used. Although the displacement decreases for higher speeds the velocity level is still considerable. 


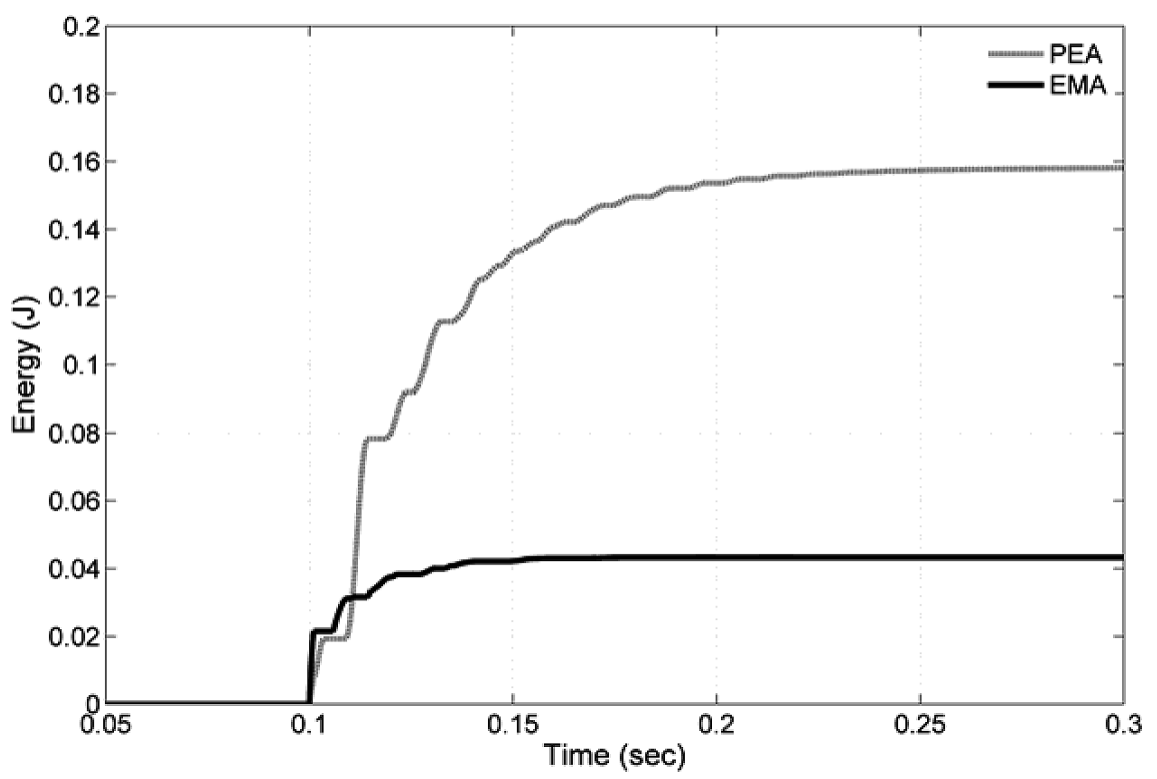

Fig. 10. Total energy consumed, impact excitation.

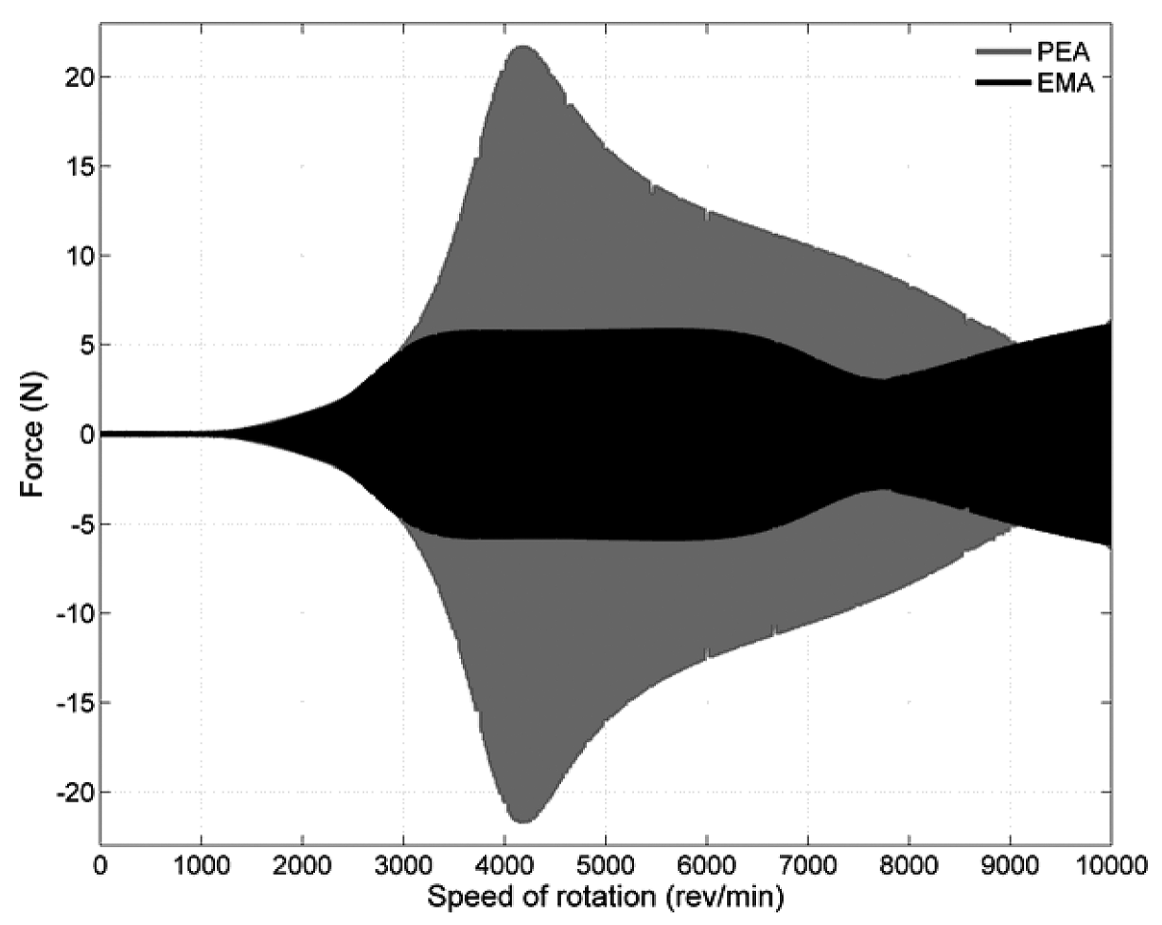

Fig. 11. Command forces during acceleration from 0 to $1000 \mathrm{rev} / \mathrm{min}(252 \mathrm{rev} / \mathrm{min} / \mathrm{sec})$.

On the other hand no low pass filters were utilized for the simulated displacements, though the use of such filters could enhance controller performance. The aim in this work is to compare the performance of the two actuators under similar conditions despite them not being optimal. It is also worth mentioning that it is important to compare the energy consumption for different control strategies [31]. 


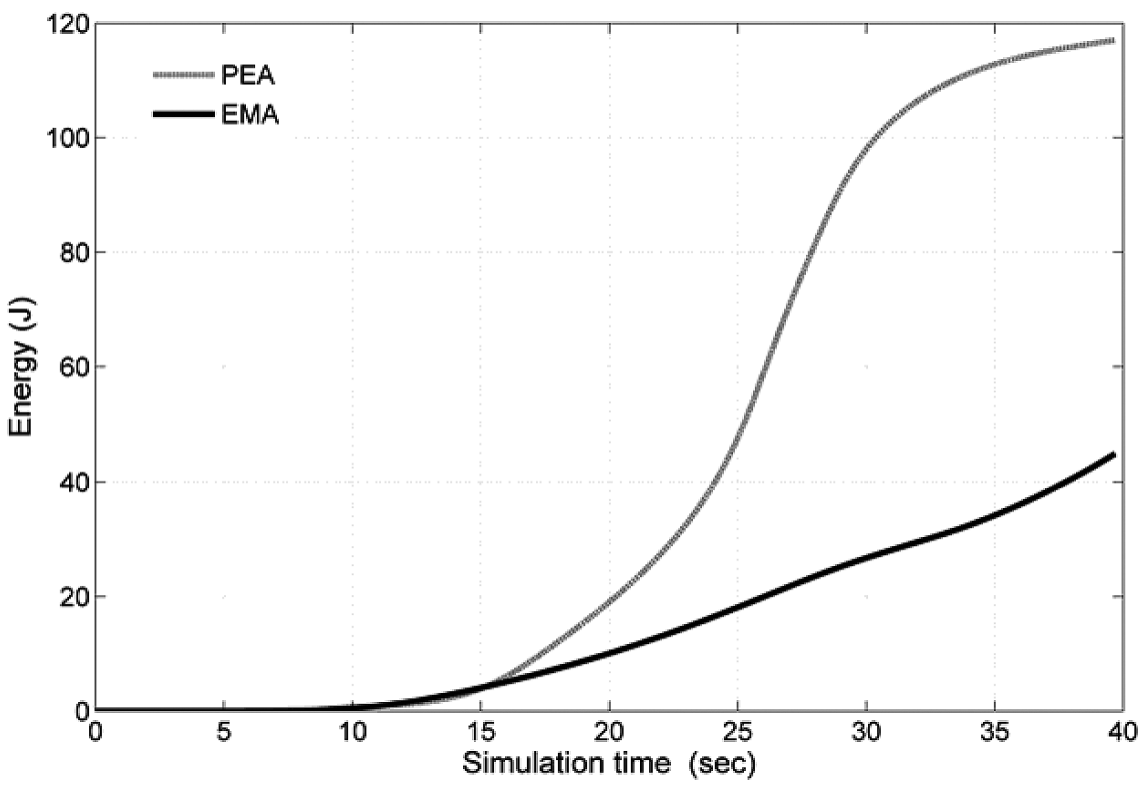

Fig. 12. Total energy consumed during acceleration from 0 to $1000 \mathrm{rev} / \mathrm{min}(252 \mathrm{rev} / \mathrm{min} / \mathrm{sec})$ for EMA and PEA.

\section{Conclusion}

Environmental issues have become increasingly important in decisions regarding energy policy. The aim of this study is to examine the possibility of applying selection criteria based on energy consumption. Numerical simulations were carried out in order to quantify and compare the energy consumed for controlling a rotating machine by using either EMA or PEA. Simplified models of the actuators based on basic electricity theory were used. It is worth mentioning that the dynamic behaviors of the rotating machine were not identical due to the technology of each actuator used. Thus the comparisons were made on the basis of energy consumption for similar mechanical performances.

The energy consumptions of the two technologies used were compared in the case of impulsive force excitation, during acceleration and crossing the first critical speed. Both configurations were efficient and the energy used was relatively low. Nevertheless, and for the conditions fixed for this study, EMA seems to be the more "environmentally friendly technology". This is due to the fact that both actuators (with the control loop) mainly introduce damping. The control force necessary in this case depends on the structure's stiffness; it is as great as the stiffness is high.

Furthermore, both actuators continue controlling and consuming energy even for rotation speeds higher than the critical speed where the displacement levels decrease significantly. The use of continuous control becomes costly (for both actuators). The control approach applied also plays an important role; a pre-informed control approach where the actuators are only activated near critical speeds is an interesting alternative solution.

It is obvious that the energy consumed by both actuators is negligible compared to the energy used to accelerate the rotor or make it run at constant speed. The aim is not to present a control technology intended to reduce environmental effects, but solely to consider energy cost when comparing two efficient control technologies.

The comparison must be performed by quantifying the environmental impacts of the actuators over their full life-cycle, from "cradle to grave".

\section{Acknowledgement}

Authors thank Professor Daniel Froelich, Laboratory "Eco-Conception et Management Environnemental" from ENSAM Chambery, for his invaluable advices and remarks. 


\section{References}

[1] H.A. Udo De Haes and R. Heijungs, Life cycle assessment for energy analysis and management, Applied Energy, Elsevier 84 (2007), $817-827$.

[2] A. Niederl-Schmidinger and M. Narodoslawsky, Life Cycle Assessment as an engineer's tool?, Journal of Cleaner Production, Elsevier 16 (2006), 245-252.

[3] ISO, 1997, Environmental Management. Life cycle assessment: principles and framework, EN ISO 14040.

[4] V. Fthenakis, W. Wang and H.C. Kim, Life Cycle Inventory Analysis of the Production of Metals used in Photovoltaics, Renewable \& sustainable energy reviews, Elsevier. ISSN: 1364-0321, 2007.

[5] P.E. Fitch and J.S. Cooper, Life Cycle Energy Analysis as a Method for Material Selection, Transaction of the ASME, Journal of Mechanical Design 126 (2004), 798-804.

[6] M.D. Bovea and A. Gallardo, The influence of impact assessment methods on materials selection for eco-design, Materials \& Design Elsevier 27 (2006), 209-215.

[7] W. Amatayakul and O. Ramnas, Life cycle assessment of a catalytic converter for passenger cars, Journal of Cleaner Production Elsevier 9 (2001), 395-403.

[8] A. Stoppato, Life Cycle assessment of photovoltaic electricity generation, Energy, Elsevier 33 (2008), $224-232$.

[9] C. Bauer, J. Buchgeister, R. Hischier, W.R. Poganietz, L. Schebek and J. Warsen, Towards a framework for life cycle thinking in the assessment of nanotechnology, Journal of Cleaner Production, Elsevier 16 (2008), 910-926.

[10] E.H. Maslen, P.E. Allaire, M.D. Noh and C.K. Sortore, Magnetic Bearing Design for Reduced Power Consumption, Transaction of the ASME, Journal of Tribology 11 (1996), 839-846.

[11] M.H. Holdhusen and K.A. Cunefare, Optimization of a state-switched absorber applied to a continuous vibrating system, The Journal of the Acoustical Society of America 109(5) (2001), 2351-2352.

[12] F. Matichard and L. Gaudiller, Improvement of potential energetic exhange using non linear control, IEEE/ASME, AIM - Advanced Intelligent Mechatronics (2005), 807-812.

[13] C. Richard, D. Guyomar and S. Mohammadi, Semi-passive random vibration control based on statistics, Journal of Sound and Vibration 307 (2007), 818-833.

[14] G. Schweitzer, H. Bleuler and A. Traxler, Active Magnetic Bearings - Basics, Properties and Applications, vdf Hochschulverlag AG, ETH, Zurich, 2003.

[15] S. Lei and A. Palazzolo, Control of flexible rotor systems with active magnetic bearings, Journal of Sound and Vibration (2008) doi:10.1016/j.jsv.2007.12.028.

[16] M. Kasarda, J. Marshall and R. Prins, Active magnetic bearing based force measurement using the multi-point technique, Mechanics Research Communications 34 (2007), 44-53.

[17] G. Mani, D.D. Quinn and M. Kasaeda, Active health monitoring in a rotating cracked shaft using active magnetic bearings as force actuators, Journal of Sound and Vibration 294 (2006), 454-465.

[18] M. Aenis, E. Knopf and R. Nordmann, Active magnetic bearings for the identification and fault diagnosis in turbomachinery, Mechatronics 12 (2002), 1011-1021.

[19] M. Kasarda, H. Mendoza, R.G. Kirk and A. Wicks, Reduction of subsynchronous vibrations in a single-disk rotor using an active magnetic damper, Mechanics Research Communications 31 (2004), 689-695.

[20] M.N. Sahinkaya and C.R. Burrows, Control of stability and the synchronous vibration of a flexible rotor supported on oil-film bearings, Journal of Dynamic Systems Measurement and Control, Transactions of the ASME 107 (1985), 139-144.

[21] A. El-Shafei and A.S. Dimitri, Controlling Journal Bearing Instability using Active Magnetic Bearings, Proceedings of ASME Turbo Expo, GT2007-28059, Canada.

[22] H.S. Tzou, Active Vibration Control of Flexible Structures Via Conserve Piezoelectricity, (Vol. 14-c,) Proceedings Of 20th Midwestern Mechanics Conference, Developments in Mechanics, 1987, pp. 1201-1206.

[23] A. Baz and S. Poh, Performance of an Active Control System with Piezoelectric Actuators, Journal of sound and Vibration $126 \mathrm{~N}^{\circ} 2$ (1988), 327-340.

[24] H.G. Horst and H.P. Wölfel, Active Vibration Control of a High Speed Rotor Using PZT Patches on the Shaft Surface, Journal of Intelligent Material Systems and Structures 15 (2004), 721-728.

[25] A.B. Palazzolo, S. Jogannathan, A.F. Kascak, G.T. Montague and L.J. Kiraly, Hybrid Active Vibration Control of Rotor Bearing Systems Using Piezoelectric Actuators, Journal of Vibration and Acoustics 115 (1993), 111-119.

[26] A. Alizadeh, C. Ehmann, U. Schönhoff and R. Nordmann, Active Bearing of Rotors Utilizing Robust Controlled Piezo Actuators, Proceedings of DETC'03, Chicago, Illinois, 2003, Sep. 2-6.

[27] R.C. Simôes, J. Der Hagopian, J. Mahfoud and V. Steffen, Jr, Modal Active Vibration Control of a Rotor using Piezoelectric Stack Actuators, Journal of Vibration and Control 13(1) (2007), 45-64.

[28] M. Mahlis, L. Gaudiller and J. Der Hagopian, Fuzzy Modal Active Control of the Dynamic Behavior of Flexible Structures, Journal of Vibration and Control 11 (2005), 67-88.

[29] M. Malhis, Contrôle actif modal flou des rotors flexibles par plan d'action piézoélectrique, Ph.D. thesis, http://docinsa.insalyon.fr/these/pont.php?\&id=malhis, 2002.

[30] P.Y. Couzon and J. Der Hagopian, Neuro-Fuzzy active control of rotor suspended on active magnetic bearing, Journal of Vibration and Control 13(4) (2007), 365-384.

[31] J. Der Hagopian and J. Mahfoud, Numerical and Experimental Investigation of the Active Control by Using Electromagnetic Actuator, Proceedings of the XIII International Symposium on Dynamic Problems of Mechanics (DINAME 2009), Brazil, 2009. 

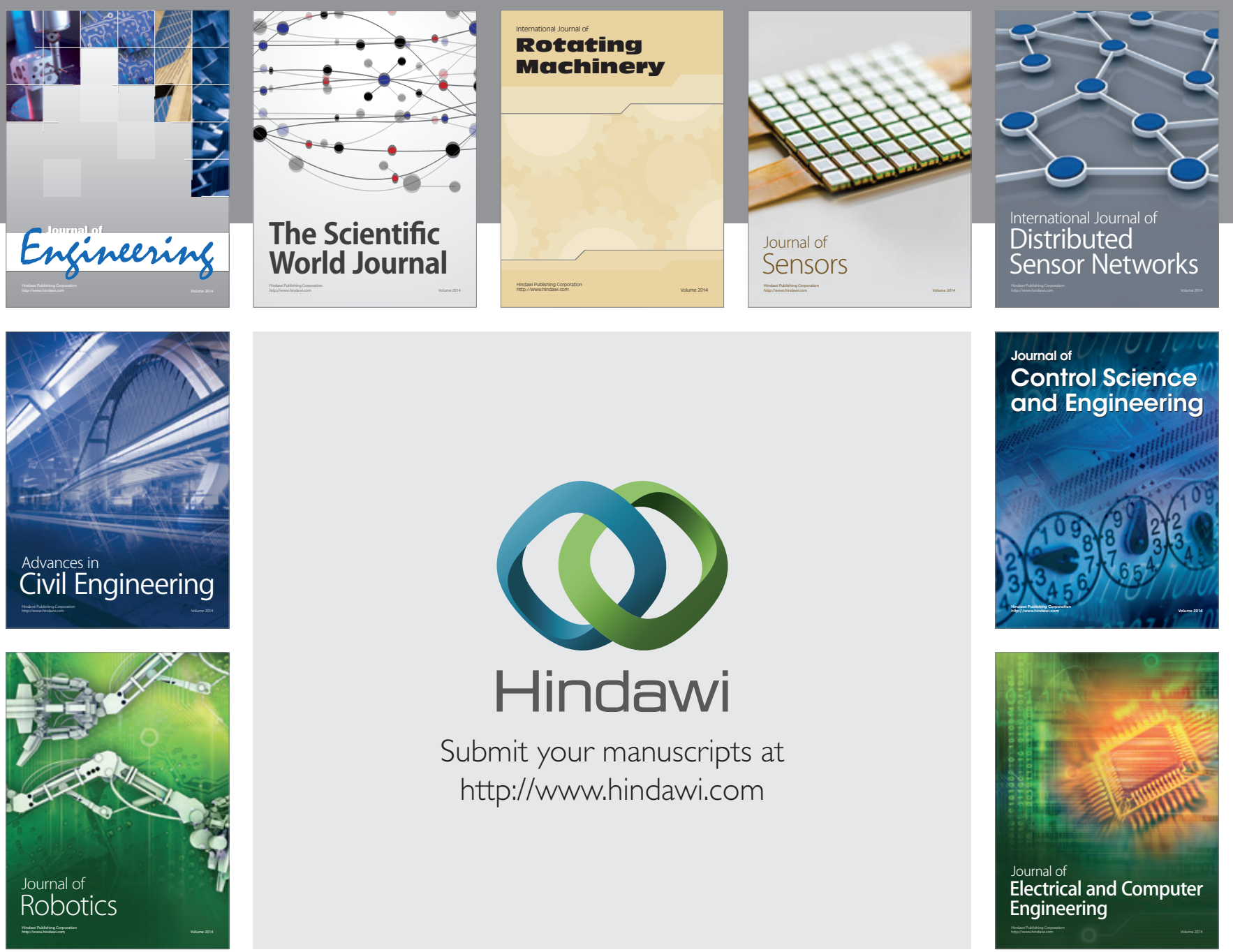

Submit your manuscripts at

http://www.hindawi.com
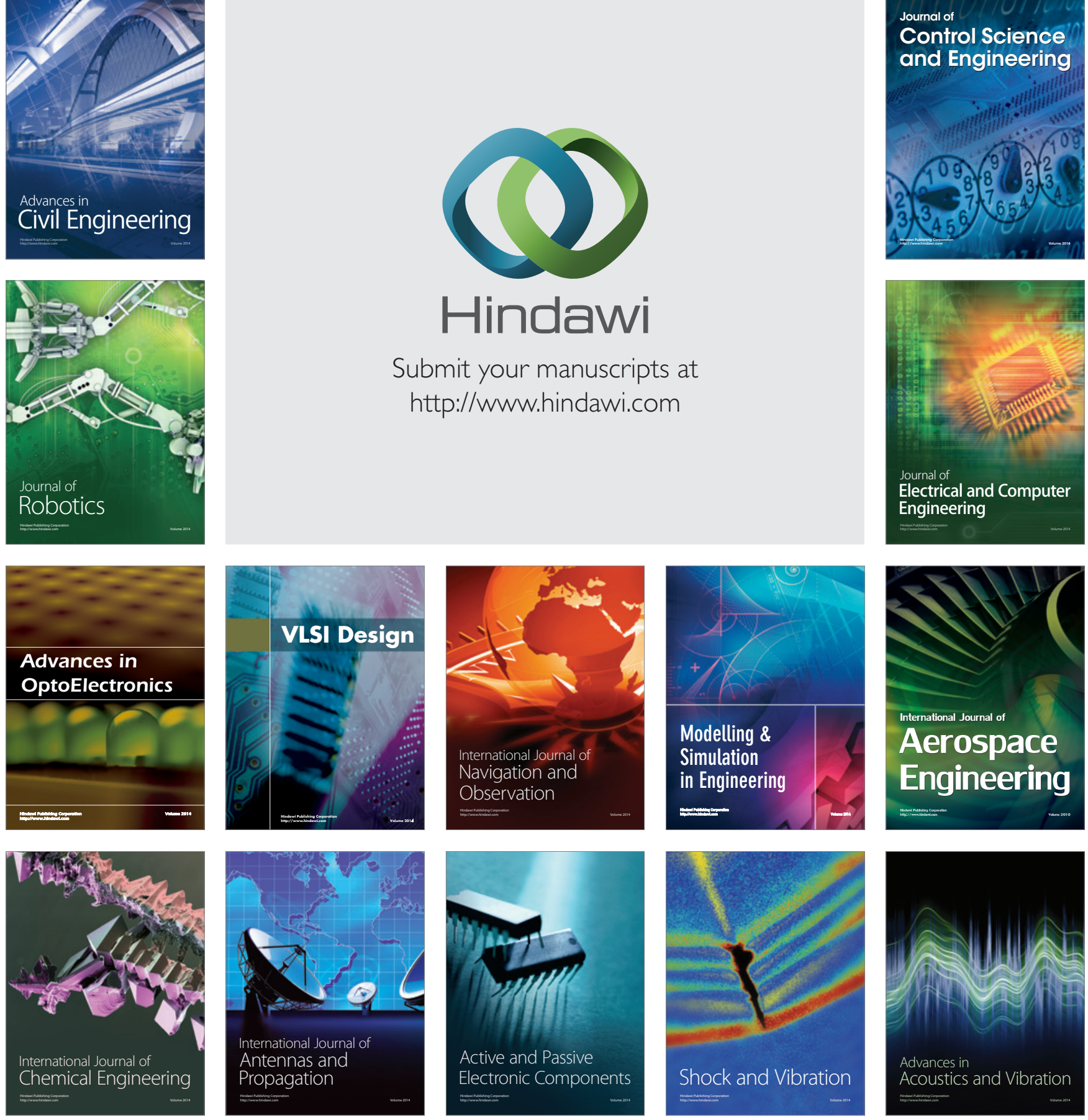